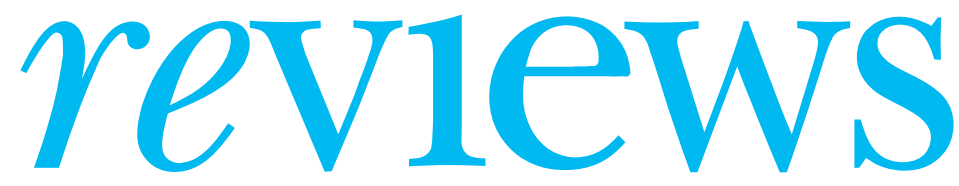

BOOKS • CD ROMS • ART •WEBSITES • MEDIA $\bullet$ PERSONAL VIEWS $\bullet$ SOUNDINGS

\section{The Truth About the Drug Companies: How they deceive us and what to do about it \\ Marcia Angell

\begin{tabular}{|c|c|}
\hline $\begin{array}{l}\text { The Truth About } \\
\text { the Drug Companies }\end{array}$ & $\begin{array}{l}\text { Random House, \$24.95, } \\
\text { pp } 336 \\
\text { ISBN } 0375508465 \\
\text { Also available as an ebook, } \\
\$ 17.95 \\
\text { www.randomhouse.com }\end{array}$ \\
\hline $\begin{array}{l}\text { HOW THEY OEcEIVE US } \\
\text { aND WHAT TO DO ABOUT IT }\end{array}$ & Rating: $\star \star \star \star \star$ \\
\hline MARCIA ANGELLL. M.D & \\
\hline
\end{tabular}

$\mathrm{D}$ Marcia Angell, a member of Harvard Medical School's Department of Social Medicine, has written a painstakingly researched book on the wiles and ways of what has come to be called "big pharma." It is a clear exposé of the American drug industry and is written in the impassioned but impeccable prose we expect from a former editor of the New England Journal of Medicine.

Angell says that \$200bn (£110bn; $€ 165 \mathrm{bn})$ is spent annually on prescription drugs in the United States. With the cost rising $12 \%$ a year, it is the fastest growing part average price of the 50 commonest drugs used by elderly people was nearly $\$ 1500$ for a year's supply. At, say, six prescriptions-not an uncommon number among elderly Americans-that's $\$ 9000$ a year for one person's drugs. What are the remedies for this unaffordable financial burden? Choose between food, fuel, or drugs? Take half of America's swollen health bill. In 2002 the

doses? Take a trip to Canada to buy cheaper drugs? Or ignore your doctor's prescriptions altogether?

To deal with this dilemma the US Congress passed the Medicare Reform Bill at the end of 2003, with a drug benefit to begin in 2006-but this is already inadequate, as it's been overtaken by sharply rising costs.

Angell says that public resentment and resistance to these consumer rip offs has been growing. Big pharma's response has led not to drug discounts but to public relations ploys justifying bloated prices, mainly involving the three marketing mantras: research, innovation, and free enterprise in the interests of shareholders. She points out that the United States is the world's major profit centre for drugs. Big pharma relocates here from other countries "to feed on the unparalleled research output of American universities and the [taxpayer funded] National Institutes of Health."

For two decades the drug industry was the most profitable sector; even in 2003 it came third, behind crude oil and banking. But now, Angell says, it is facing "a tidal wave of government investigations and civil and criminal lawsuits."

She writes, "The litany of charges includes illegally overcharging Medicaid and Medicare, paying kickbacks to doctors, engaging in anticompetitive practices, colluding with generic companies to keep generic drugs off the market, illegally promoting drugs for unapproved uses, engaging in misleading direct-to-consumer advertising, and, of course, covering up evidence. Some of the settlements have been huge."

The book's 13 chapters examine the drug industry's exaggerated claims of producing new drugs and its barrage of media marketing disguised as consumer education. Actually, big pharma's main business is in

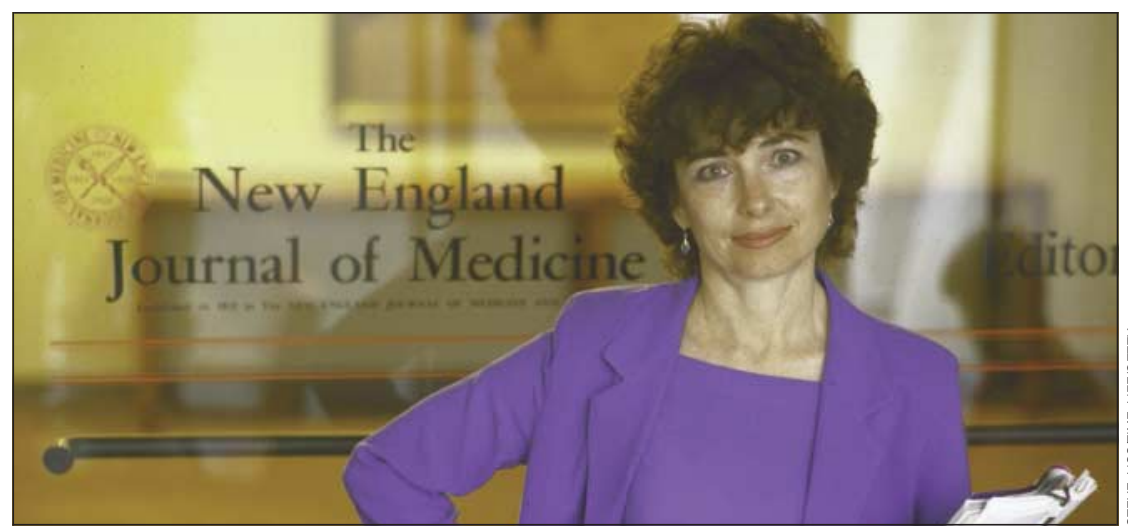

Dr Marcia Angell: her exposé of big pharma is an important public service producing what are called "me too" drugs: merely variations of old drugs created to prolong patent rights and to grab market share.

Angell remembers the philosopher Immanuel Kant: "Physicians think they do a lot for a patient when they give his disease a name." And she writes, "As the whole world knows, there is now a condition recently christened 'erectile dysfunction,' and a drug, Viagra [sildenafil], and two me-toos, Levitra and Cialis, to treat it. Advertisements for these drugs feature not decrepit old men but young athletes. The implication is obvious. Any episode of impotence, no matter how rare and how mild, is 'erectile dysfunction, there is a pill for it, and if this macho quarterback is not too embarrassed to ask for it, you don't have to be either."

Less profitable drugs-those against malaria and tuberculosis, for examplereceive much less attention. The Bush administration, friendly to big pharma, "has refused to allow any of the promised $\$ 15 \mathrm{bn}$ in federal funds allotted for HIV/AIDS treatment in the Third World to be spent on generic drugs."

Among the many wiles exposed are big pharma's use of contract research organisations to exert undue influence over clinical research and its insidious seduction of doctors. In 2001 drug companies gave doctors nearly $\$ 11$ bn worth of "free samples." This was in addition to the "food, flattery, and friendship" provided by drug company representatives to doctors (BMJ 2003;326:1189).

The final chapter, "How to Save the Pharmaceutical Industry-And Get Our Money's Worth," gives seven essential reforms, chief of which is for the Food and Drug Administration to compare new drugs not with placebos but with old drugs, to see whether there are any additional benefits.

Angell's goal is access to good drugs at reasonable prices, which requires public pressure to spur the government to action against big pharma's powerful and ubiquitous lobbyists (more numerous than the members of Congress) and its political campaign contributions. She has performed an important public service in focusing on the drug companies and their disingenuousness. The reform of big pharma starts with a public outcry against the abuses she has shown. And here doctors should stand by their patients, not their purses.

Fred Charatan retired geriatric physician, Florida charatanf@bellsouth.net

Items reviewed are rated on a 4 star scale (4=excellent) 
Aill

\section{Future Face}

An exhibition at the Science Museum, London SW7, from 1 October 2004 until 13 February 2005. Admission free www.sciencemuseum.org.uk/exhibitions/ futureface/

\section{Rating: $\star \star \star \star$}

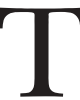
he Science Museum has had to evolve as science and its relationship with the public have become more sophisticated. "Future Face" is a great example of how it has grown up-a blend of art and science that really gets you thinking about what faces are, what they mean, and what they might look like in the future. For the traditionalists there are still some texts and even a few (awesome) buttons to pressjust don't expect to go home with all the answers.

The "Future Face" project is the brainchild of Sandra Kemp, director of research at the Royal College of Art, and it has taken her five years to bring together. Unlike many trendy "arts meets science" projects, where the art is simply there to "sex up" the science, this one really works because scientists and artists have been pondering the mysteries of the face in their different ways for thousands of years. Kemp has supplemented her own expertise in literature and the visual arts with material from physiognomy (the study of how facial features and expression relate to character), psychology, anatomy, medicine, and advanced imaging and digital technologies.
As you wander into the exhibition, you are confronted by a wall of about 200 mirrors-a neat motif for the entire exhibition-and a series of intricately sculpted heads showing how we think the human skull and face have evolved over millions of years. It is made clear that much of the evolution of the face is still a mystery. The development of individual sense organs, for example, helped to shape the face, but so did the ability of the whole face to convey non-verbal communication. Anatomy fans will not be disappointed-on display are a depiction of Gunter von Hagens' plastinated vascular system of the head, and a Charles Bell 1824 drawing of the muscles of the face. We learn how our thousands of different facial expressions depend on the complex co-ordination of nerves and muscles-and that even the colour, lines, and texture of the skin are a barometer of a person's age, health, and experience. But the relation of the face muscles to expressions is not completely understood-no wonder the face is such a compelling subject for both artist and scientist.

One of the most arresting sections deals with the relationship between facial appearance and thought, feeling, and consciousness. I found myself glued to the spot, gawping at a specially commissioned video installation by Christian Dorley-Brown. The piece consists of two 15-second video portraits of each subject, shown side by side, the first taken when they were age 10 , the second age 20. Dorley-Brown asked them to express themselves entirely through facial expression. It was a powerful meditation on the passage of time and the loss of childhood innocence-all told through the face. Although there are many theories about how we interpret and identify faces, I was left with the impression that art has at least as much to say on the subject as science.

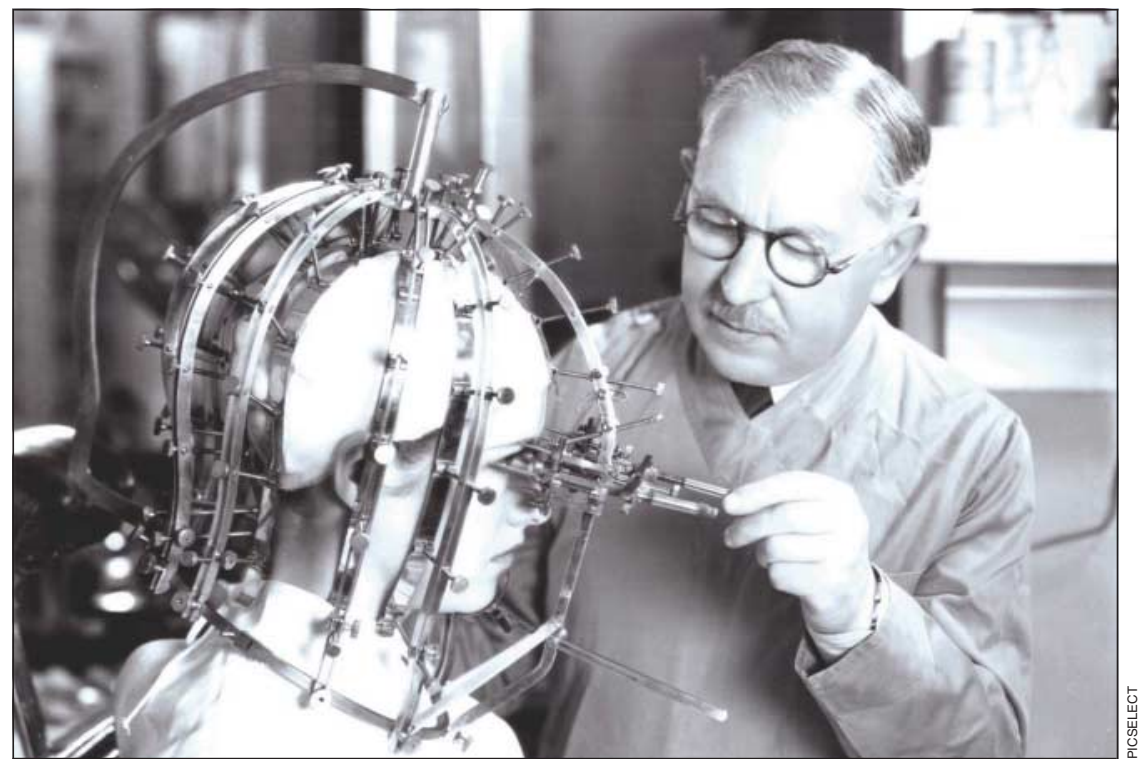

The Max Factor Beauty Calibrator (1932), said to be able to measure good looks to the hundredth of an inch

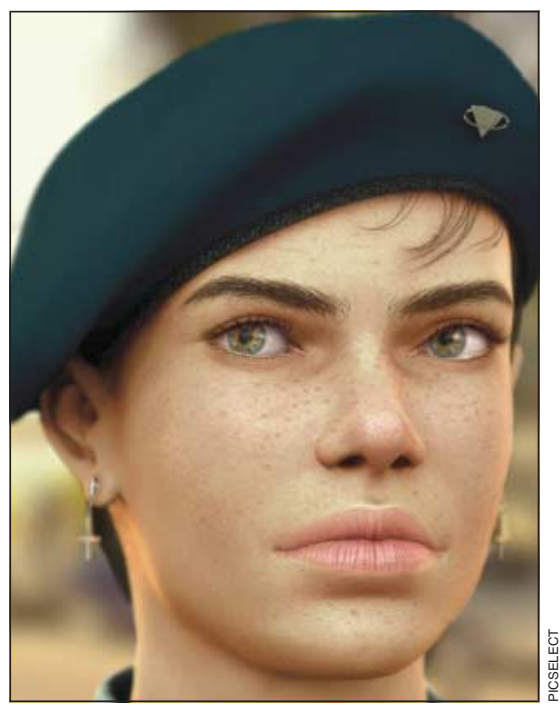

Kaya, one of the world's first digital models

Part of the exhibition is devoted to the history and development of face prostheses and facial surgery. There are the predictable portraits and photos of people with facial deformities, but some are strikingly cheerful and beautiful, as if calculated to challenge assumptions and prejudices. You can also see some of the remarkable sketches by the artist Henry Tonks, who in 1916-17 recorded the severe facial injuries of casualties from the Western Front in his work with the plastic surgeon Harold Gillies at Aldershot. Around the same time, the sculptor Francis Derwent Wood was making prosthetic masks at the Masks for Facial Disfigurement Department (or "Tin Noses Shop") at the 3rd London Hospital. We see how plastic (or aesthetic) surgery has moved on-now it is very high tech, but art still plays a big part. And these days we don't just have surgery for severe disfigurement; Britons spend more than $£ 225 \mathrm{~m}(\$ 402 \mathrm{~m}$; €327m) a year on cosmetic surgery-one of the most common reasons women give for nonproperty loans-and 1 in 12 cosmetic surgery patients are men.

Which brings us to the big questionwhat will our faces look like in the future? Sandra Kemp feels that this will have less to do with genetics and evolution than a blend of modern microsurgical techniques (the first face transplant seems just round the corner) and clever digital technology (we now have digital newsreaders and digital models). But interestingly, the "perfect" and spooky digital faces on display just highlight how our natural, flawed, asymmetrical faces convey so much more about who we are and what we are feeling. In fact my own face, when digitally morphed at the press of a button to show what I would look like as a wrinkled old man, seemed to be a dramatic improvement on the current version. Worth a visit if only to press that button.

Graham Easton assistant editor, BM] geaston@bmj.com 


\section{NETLINES}

- From the Department of Family and Social Medicine at the Albert Einstein College of Medicine, New York, comes a social medicine portal (www.socialmedicine.org), which contains a rich seam of links and documents and is an excellent launch pad from which to explore this topic online.

- Having problems getting to grips with electrocardiograms? Then have a look at the Alan E Lindsay ECG Learning Center (http://medstat.med.utah.edu/kw/ecg/ ecg outline/index.html). The site is neatly divided into 12 online chapters that are accessed through a simple descriptive hypertext index. There are chapters on the normal ECG and on disease states, such as ventricular hypertrophy, myocardial infarction, and T wave abnormalities. One chapter describes a method of interpreting an ECG. Bookmark this page if you want to demystify ECGs or if you want to refresh your memory banks.

- It comes as no great surprise that the Bloodline site, with its blood red banner, is an online haematology resource. Within the site is an excellent haematology atlas (http://image.bloodline.net/category) that contains images of a large collection of haematology slides laid out in a simple hypertext descriptive index-you just click on a topic and make your choice. The images seem to be of good quality, and with a great number of items on display the site is a good educational and reference resource. Also take a tour of the host's portal, as it has plenty of interesting material.

- PowerPoint slide collections are always useful for educators, and the Royal College of Physicians website has an excellent collection from the college's tobacco advisory group (www.rcplondon.ac.uk/ pubs/books/tag/index.asp). The site has eight presentations to download, described as suitable for use with medical students and junior doctors. If you want all of them you can download a zipped file containing the whole collection. The collection covers the topic well, with subjects including smoking cessation, nicotine addiction, and questions that smokers ask.

- Not all hospitals and healthcare facilities offer palliative care services. If there is an interest in creating such a service in your area, the Center to Advance Palliative Care (www.capc.org) may be able to help. Although it is a US site, it has elements that will appeal globally, available from the menu options on the home page. Many people will find the resources section rich in material related to palliative care in general-not just to setting up or improving a service. These include links to journals and a number of associated palliative care resources.

Harry Brown general practitioner, Leeds DrHarry@DrHarry.co.uk

We welcome suggestions for websites to be included in future Netlines. Readers should contact Harry Brown at the above email address

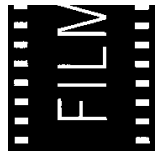

\section{Film reopens euthanasia debate in Spain}

A film based on a true story of assisted suicide has unexpectedly rekindled the ethical, medical, and political debate about legalising euthanasia in Spain. Mar Adentro (The Sea Inside) focuses on the death six years ago of Ramón Sampedro, a sailor who became quadriplegic after injuries sustained when he was 25 years old.

The huge media impact that the film had when it opened in Spain last month has made it possible for the main groups supporting and opposing euthanasia to express their positions publicly. The Catholic church has stood by its view that euthanasia is "immoral and antisocial"; the country's Socialist government has been forced to make a statement; and finally the issue has reached the Spanish parliament.

Mar Adentro, directed by Alejandro Amenábar, has been highly acclaimed and won the special jury award at the Venice Film Festival. But even the film's artistic merits are surpassed by the poignancy of Ramón Sampedro's story. Sampedro, who spent half his life on a bed, unable to move, became a charismatic figure thanks to his insight and his unsuccessful fight with the Spanish legal system for the right to a decent death.

"I consider life a right, not an obligation, as it is in my case. I have been forced to endure this terrible situation for 29 years, four months and a few days. After all this time, when I evaluate what I have been through, I do not get happiness as an end result." These were Sampedro's words in a video taped minutes before he drank the cyanide that killed him.

Every year in Spain more than 200 people with terminal illnesses ask for help to

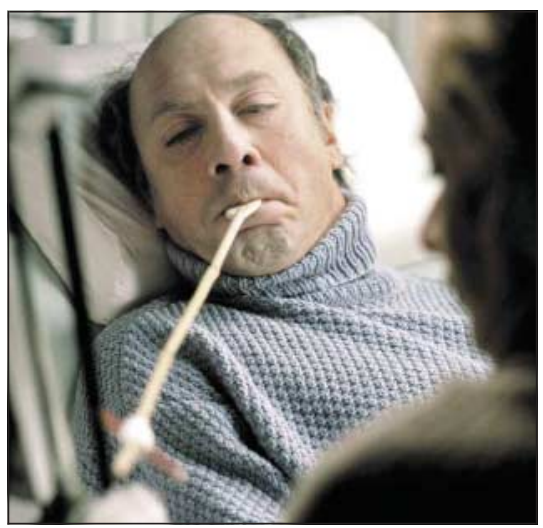

Immobile: Javier Bardem as Ramón Sampedro die. Spanish law deems assisted suicide and euthanasia as crimes, even though it allows suicide (survivors remaining unpunished). In Sampedro's case, more than 2000 people confessed to having helped him obtain the cyanide. Finally, the court decided to close its investigation without pressing any charges.

The Spanish prime minister, José Luis Rodríguez Zapatero, who attended the premiere of Mar Adentro with some of his cabinet ministers, has said that he "probably would not" have helped Sampedro to die. Although the right to euthanasia is on the Socialists' agenda, Zapatero has said that there is no time earmarked to meet this commitment and that following Belgium and the Netherlands (the only two countries in Europe that have legalised euthanasia) is not a priority.

The Association for the Right to Die with Dignity-Spanish acronym DMD-which features in the film, saw the presence of government members at the premiere as promising. DMD's president, the writer Salvador Pániker, has said he thinks "society is a lot more mature than the politicians" and has highlighted the fact that "surveys show that $70 \%$ of the population is in favour of euthanasia."

Hay Alternativas (There Are Alternatives), a group that opposes euthanasia and abortion, has labelled the film "an ode to death" and has declared that the information given in the film is biased.

Director Alejandro Amenábar has said that his film is not a demand for euthanasia, and its only aim is to confront the audience with the abyss of death. "It's more a reflection than a demand. I am sure that euthanasia will be regulated in the future and I do not want this film to lose its validity."

Sampedro's story is a wise blend of emotion, drama, and humour. "I am just a head stuck to a body," he says in the film. "For me, those crucial couple of yards to get to you and be able to touch you are an impossible trip, an illusion, a dream ... And that is why I want to die."

Actor Javier Bardem, who won the best actor award at the Venice festival for his portrayal of Sampedro and who only moves his head and neck in the film, has said: "The immobility that I had to endure while we were filming helped me understand Ramón's torture and his helplessness."

The Federación de Asociaciones de Defensa de la Sanidad Pública-a group of doctors and health professionals-has demanded an urgent regulation of euthanasia and assisted suicide. The more conservative Organización Médica Colegial (OMC)) and the Standing Committee of European Doctors are against euthanasia.

The debate reached the Spanish parliament on 22 September, when health minister Elena Salgado said that the government would not legalise euthanasia during this term of office. However, she announced that palliative care would be improved and that steps would be taken to create a record of living wills and to avoid "therapeutic cruelty."

Gonzalo Casino medical journalist, El País, Spain gcasino@cardiel.net 
PERSONAL VIEW

\section{When TV damned the drug regulators}

$\mathrm{O}$ Sunday 3 October the BBC creened its third Panorama documentary about the antidepressant paroxetine (Seroxat). This was strongly critical of the work of the British regulatory body responsible for medicines, the Medicines and Healthcare products Regulatory Agency (MHRA). A multitude of plausible sounding experts and commentators had been assembled to impart some clear messages-there are big problems with paroxetine and the regulators have messed up big time. The programme claimed that the MHRA had overlooked vital information about paroxetine that suggested it could increase suicidal feelings in all age groups. Richard Brook, the chief executive of the charity MIND, stated on the Panorama website that the agency was "either guilty of extreme negligence or worse dishonesty"

(http://news.bbc.co.uk/1/

hi/programmes/panorama/

default.stm). That is a serious accusation and, if the thrust of this programme is correct, we should all be worried about the medicines we prescribe, recommend, or take.

To be told on television that I and many colleagues do not care is galling

- the regulatory system is not perfect either but the people working within it do their best to balance risks and benefits and are solely driven by public health and patient considerations

- there is a need to consider what other bodies are doing internationally (less and more slowly than the MRHA).

It is now clear that the producers did not accept the first three messages and they completely ignored the fourth. Although the producers were courteous and friendly, it seems as if they set out to damn the regulators.

The interview with Panorama was not a pleasant experience. Reporter Shelley Jofre's harassing tone should not have come as a shock (but it did) and she rapidly strayed beyond the agreed boundaries of what I felt able to cover. Just over a week before the programme I received a call from the producer-they had succeeded in interviewing the MHRA's chairman, Sir Alasdair Breckenridge, and therefore had cut me and five others out of the programme. Rather selfishly, I was delighted-who really wants to appear on Panorama?

I have some limited

insight into the making of this programme. I met with the producers informally and then sat in front of their cameras for about 90 minutes answering questions on a wide range of issues. They approached me because I worked at the Medicines Control Agency (as it then was) from 1990 to 2002 and because they had not yet managed to interview anyone from the MHRA. They said they wanted to hear the "other side."

I tried to explain some of the difficulties involved in deciding cause and effect, particularly when the putative effect ("suicidality") is a consequence of the illness for which the drug is prescribed. I also explained in detail the process of postmarketing surveillance, its strengths and limitations, and some relevant initiatives. I indicated that my view was that there were no grounds for secrecy in relation to data on drug safety and said that major change was taking place in this respect (the UK secrecy law relating to medicines is being repealed from 1 January 2005). I showed them a report produced in 2003 by the National Audit Office (NAO), which was generally favourable to the MHRA but made some constructive criticisms. The NAO is not known for pulling its punches when it comes to criticising government bodies. I endeavoured to convey some balanced messages:

- there are some problems with paroxetine, the jury is out, and the issues are being, and have been, taken seriously

- the surveillance system is not perfect but people are trying to improve it
In the end I was staggered by how one sided the programme was and disappointed that I had effectively wasted my time with the programme makers. Their almost total reliance on temporal association as the sole criterion for causality was striking. Difficult and debatable issues were presented as facts and several participants must have been a "dream" for the programme makers. Periodically saying that "Seroxat has helped millions" and "do not stop your treatment" did not offset the hugely biased approach. I wonder how many patients would inappropriately stop treatment and how many unnecessary consultations there would be in the coming weeks.

Regulators must expect criticism-it goes with the job. They should defend themselves when experts or television producers tell them they have got it wrong. However, when such people claim, without presenting any evidence at all in support, that patients are their last priority, they have a right to be angry.

I last saw a patient about 16 years ago but I still care passionately about patient safety. To be told on national television that I and many colleagues do not care is galling beyond measure. Neither the drug nor the regulator is lilywhite but the reporting is surely the most dangerous offender here. pharmacoepidemiology, Southampton patrick.waller@btinternet.com

Competing interests: PW was previously employed at the Medicines Control Agency and currently holds a contract to consult for the MHRA.

\section{Patrick Waller consultant in}

SOUNDINGS

\section{The Welshman in the temple}

The Welshman was very old and very, very upset. He crouched in his wheelchair, waving his stick and shouting. "What's all this then? What are they doing here? Who let them in?" The elderly woman pushing his wheelchair leaned over. "Not sure, dear... But it seems to be the modern way." "Modern be buggered," he shouted. "I'm not having it." Passers-by ignored him or just cringed. A pale youth with one arm in a sling sprang backwards to avoid the flailing walking stick and dropped his Starbucks cappuccino grande.

"Sorry, boyo. I'm really sorry." The old man's smile was charm itself. "I'll get them to clean that up for you. And how's the NHS treating you? I want to know .. It's your arm, isn't it?' The youth bit his lip and sniffed. "Not good, eh? Oh dear."

"Terrible, terrible ..." said the old man a few minutes later. "Who'd have thought it? And the price he paid for that coffee!"

"The money's different now," said his minder rather sharply. "And we'd better be getting on."

"But what's all this ... A lawyer's office? Two banks? And three extortionate coffee shops? Each one exploiting the working man ... And a right flashy hairdresser ... exploiting the women, eh? I don't like it at all." By now his wheelchair was speeding towards the door.

"Stop, Jenny ... Stop! What's this? In one of $m y$ hospitals?" By the door a pair of Securicor men, dressed for Star Wars, were emptying the daily takings from a parking payment point. A torrent of pound coins clattered into their treasure chest. "So what's all that about?" "It's the parking money," said his minder. "What? They even take money for the parking?"

Again his stick flew, scattering the men in armour. Two security guards in bullet-proof vests set out across the hospital mall, but were pre-empted by the hospital chaplain, who leaned over and whispered something that seemed to calm our ancient visitor. His eyes twinkled. His shock of white hair was somehow familiar. "It's the what? The PFI?" He smiled. "Not the NHS? Nothing to do with $m y$ NHS, right? Oh, that's all right then." And then NHS founder Nye Bevan, his stick, and his minder all suddenly disappeared-leaving only a wheelchair, a ghost of a smile, and a faintly disturbing memory of 1948 .

Colin Douglas doctor and novelist, Edinburgh 